\title{
Induction of p53 Accumulation by Moloney Murine Leukemia Virus-ts1 Infection in Astrocytes Via Activation of Extracellular Signal-Regulated Kinases 1/2
}

\author{
Hun-Taek Kim, Serban Tasca, Wenan Qiang, Paul K. Y. Wong, and George Stoica
}

Department of Veterinary Pathobiology (H-TK, ST, GS), Texas A\&M University, College Station, and Department of Carcinogenesis (WQ, PKYW), The University of Texas M.D. Anderson Cancer Center Science Park-Research Division, Smithville, Texas

SUMMARY: We previously reported that Moloney murine leukemia virus-ts 1 -mediated neuronal degeneration in mice is likely a result of both loss of glial support and release of cytokines and neurotoxins from ts 1 -infected glial cells. Viral infection in some cell types regulates expression of p53 protein, a key regulator of cell proliferation and death. Therefore, we hypothesized that p53 and its dependent genes may be linked with $t s 1$-mediated neuropathology. We examined the presence of p53 and its dependent gene product, a proapoptotic protein bax- $\alpha$, in ts1-induced spongiform encephalomyelopathy. Compared with controls, the lesions of infected animals contained increased levels of p53 and bax- $\alpha$ in astrocytes, as shown by strong nuclear p53 and cytoplasmic bax- $\alpha$ immunoreactivity in astrocytes. To determine how ts 1 affects $p 53$ expression in astrocytes, we then assessed the expression of p53 and its dependent genes, such as bax- $\alpha$ and p21, in infected and uninfected immortalized C1 astrocytes and studied possible pathways responsible for p53 accumulation in infected astrocytes. In these studies using mitogen-activated protein kinase inhibitors, infection-induced increases in the p53 level were partially blocked by PD98059, a synthetic inhibitor of MEK1 that is the immediate upstream kinase of extracellular signal-regulated kinases 1/2 (ERK1/2), but not by SB202190, a potent p38 kinase inhibitor. Furthermore, treatment with PD98059 significantly decreased the level of p21 protein, a p53-dependent gene product. These results suggest that ts 1 infection may stabilize p53 protein through activation of ERKs in C1 astrocytes, leading to increased expression of the p21 and bax- $\alpha$ proteins, both of which induce cell cycle arrest and apoptosis. Our studies suggest that $t s 1$ neüropathology in mice may result from changes in expression and activity of p53, brought about in part by ts1 activation of ERK. (Lab Invest 2002, 82:693-702).

$M$ oloney murine leukemia virus (MoMuLV)-TB is a murine type $C$ retrovirus that induces $\mathrm{T}$ - cell lymphomas in susceptible strains of mice (Gardner, 1978; Peters et al, 1973; Yuen and Szurek, 1989). In particular, its temperature-sensitive mutant $t s 1$, a lymphotropic, neurotropic strain of MoMuLV having a single point mutation in the envelope gene, seems to cause loss of $T$ cells and motor neurons in susceptible hosts (Szurek et al, 1990; Wong et al, 1989, 1991). MoMuLV-ts 1 infection of the brain causes a progressive neurodegenerative disease, manifested morphologically as spongiform polioencephalomyelopathy. The characteristic pathology of this condition includes astrogliosis, myelin pallor, and neuronal loss (Stoica et al, 1993). Productive ts 1 infection in the brain occurs in endothelial cells, microglia, oligodendrocytes, and as-

DOI: 10.1097/01.LAB.0000017373.82871.45

Received October 30, 2001.

This work was supported in part by National Institutes of Health grants A128283 and MH5718 (to PKYW).

Address reprint requests to: Dr. George Stoica, Professor, Department of Veterinary Pathobiology, Texas A\&M University, College Station, Texas 77843.E-mail: gstoica@cvm.tamu.edu trocytes but not in neurons (Stoica et al, 1993), implicating indirect mechanisms in ts1-mediated neuronal degeneration. In this context, neuronal degeneration may be a result of the proinflammatory cytokines and/or nitric oxide produced by ts1-infected surrounding glial cells (Choe et al, 1998; Kim et al, 2001). Studies of the ts1-induced neuropathology in this defined mouse model should provide new insights into the pathogenesis of retrovirus-induced neurodegeneration.

Virus infections affect cell division by interfering with cell cycle regulation or altering cellular gene expression. In turn, these perturbations trigger a variety of events ranging from apoptosis to transformation (Chretien et al, 2000; Genini et al, 2001; Roulston et al, 1999; Watanabe et al, 2000). Many of these changes involve alterations in p53 functions and activation of various cellular genes (Akagi et al, 1996; Cereseto et al, 1996; Yang and Prayson, 2000). Particularly, overexpression of p53 is a consistent feature of several viral infections in the central nervous system (Chretien et al, 2000; Ehsan et al, 2000; Jordan-Sciutto et al, 2000).

p53 is a transcriptional factor that plays a critical role in the regulation of growth arrest, apoptosis, and differentiation (Haffner and Oren, 1995; Levine, 1997; 
Liu et al, 1994). Regulation of the p53 protein level is achieved primarily via posttranslational mechanisms, although it may also be controlled at the transcriptional (Sun et al, 1995) and translational levels (Mosner et al, 1995). Also, p53 accumulation activates transcription of target genes, including p21, Mdm2, Gadd45, and bax- $\alpha$, leading to growth arrest or apoptosis. Studies with the human papilloma virus E6 protein and the cellular oncogene Mdm2, which interact with and lead to the degradation of p53, have shown that p53 is degraded by the ubiquitin-mediated proteolytic pathway (Haupt et al, 1997; Kubbutat et al, 1997; Storey et al, 1998). Although the signals that target p53 for degradation are not yet fully understood, it is generally accepted that p53 phosphorylation may be involved, via the mitogen-activated protein kinase (MAPK) pathway (Fuchs et al, 1998a; Keller et al, 1999; Song et al, 1998). However, a number of studies have shown that phosphorylation of p53 may contribute to its accumulation by protecting it from ubiquitination and proteolysis (Persons et al, 2000; Shieh et al, 1997; Siliciano et al, 1997).

MAPKs are cellular signaling kinases that are activated by phosphorylation of specific tyrosine and threonine residues in response to various external and internal stimuli (Dhanasekaran and Reddy, 1998; Robinson and Cobb, 1997). In mammalian cells, three general groups of MAPKs have been identified: extracellular signal-regulated kinase 1/2 (ERK1/2), c-Jun $\mathrm{N}$-terminal kinase (JNK), and p38/Hog. Activated MAPKs can phosphorylate numerous substrates, including a variety of transcription factors. In these factors, MAPK-mediated phosphorylation is a common mechanism used by the cell to induce gene expression (Lewis et al, 1998; Weitżman and Yaniv, 1998). Through their ability to regulate transcription factors, MAPKs regulate changes in the cell ranging from cell growth to apoptosis to senescence.

In cells infected by numerous viruses, one or more of the MAPKs is usually activated. For example, simian virus 40 activates ERK1/2, herpes simplex virus activates JNK and p38, and simian immunodeficiency virus activates all three MAPKs (McLean and Bachenheimer, 1999; Popik and Pitha, 1998; Yang et al, 1991; Zachos et al, 1999). MAPK activation can be induced through viral binding to the host cell, as in simian immunodeficiency virus activation of ERK $1 / 2$, JNK, and p38 kinase, or it can require viral protein synthesis, as in herpes simplex virus activation of JNK (Popik and Pitha, 1998). However, even where MAPK activation has a clear function in viral infection, little is known about how MAPK mediates this effect, and even less is known about the cellular proteins involved. An understanding of these points is therefore of great interest, because it will allow understanding of MAPK's activities in viral infection and will disclose how viruses regulate host cell machinery during infection.

In the present study, we addressed the question of whether the level of p53 is changed in astrocytes by ts 1 infection, and, if so, which mechanisms are responsible. Our results show that p53 and bax- $\alpha$ levels

are increased in the brain stem of ts 1 -infected mice. In an immortalized C1 astrocyte cell line (Lin et al, 1997), p53 accumulated via activation of the ERK pathway, rather than through p38 kinase activation, and p53dependent gene expression was increased. Inhibition of ERK by the MAPK pathway inhibitor enhanced p53 protein degradation and blocked expression of p53dependent genes. These results strongly implicate MAPK pathways in ts1-induced p53 accumulation in ts1-infected astrocytes.

\section{Results}

\section{Increased Expression of $p 53$ and bax- $\alpha$ in the Brain Stem of ts 1-Infected Mice}

We used Western immunoblotting to assess p53 expression in brain stem homogenates from control and ts1-infected mice. As shown in Figure 1 ( $\mathrm{A}$ and B), p53 was more abundant in ts 1 -infected brain stem tissues, relative to control mice, at 20 and 25 days postinfection (dpi) $(p<0.01)$. In addition, to localize p53 in the brain stem, we performed immunohistochemistry for p53 (Fig. 2). In control mice, many neurons in the brain stem were labeled, but p53 protein expression was absent or weak in glial cells (Fig. 2, A and C). By contrast, almost all of the glial cells, which were mostly astrocytes in affected areas in ts 1 -infected mice, showed moderate to strong nuclear staining for p53 (Fig. 2, B and D). In ts 1 -infected mice, no immunoreactivity for p53 was found in glial cells in other parts of the central nervous system (data not shown).

To determine whether the increased level of brain stem 053 protein occurs together with increased expression of bax- $\alpha$, a p53-reponsive gene, the level of bax- $\alpha$ was determined by immunoblotting of brain stem homogenates of control and infected mice (Fig. 3). Figure 3 ( $A$ and $B$ ) shows that ts 1 infection induced a significant increase in bax- $\alpha$ protein level at 20 and $25 \mathrm{dpi}(p<0.01)$. To localize bax- $\alpha$ in infected brain
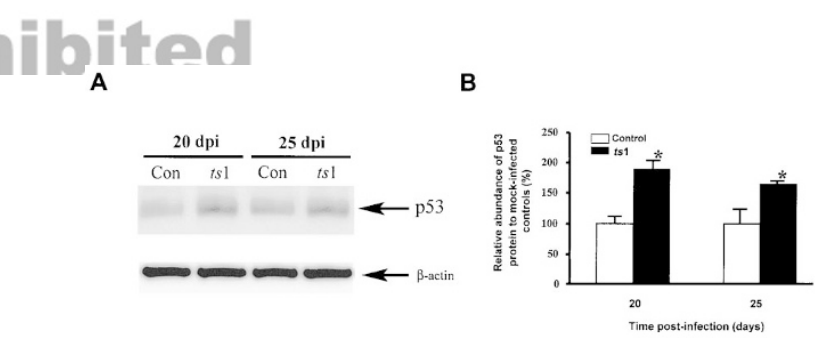

Figure 1.

Expression of $\mathrm{p} 53$ in the brain stem of control and $t s 1$-infected mice. A, Increased p53 protein in brain stem homogenates from ts 1 -infected mice. At 20 and 25 days postinfection (dpi), tissue homogenates were prepared from the brain stem of control and ts1-infected mice and then subjected to immunoblotting analysis. B, Levels of p53 in the brain stem of ts 1 -infected mice versus controls. Protein levels for bands were compared by densitometric analysis. At 20 and $25 \mathrm{dpi}$, p53 protein from brain stem tissues of ts 1 -infected mice was increased $80.1 \% \pm 18.4 \%$ and $63.7 \% \pm 8.3 \%$, respectively, over levels in control mice $(p<0.01)$. The results represented in the histogram are the mean \pm SE from tissues from three control and three ts1-infected mice. 


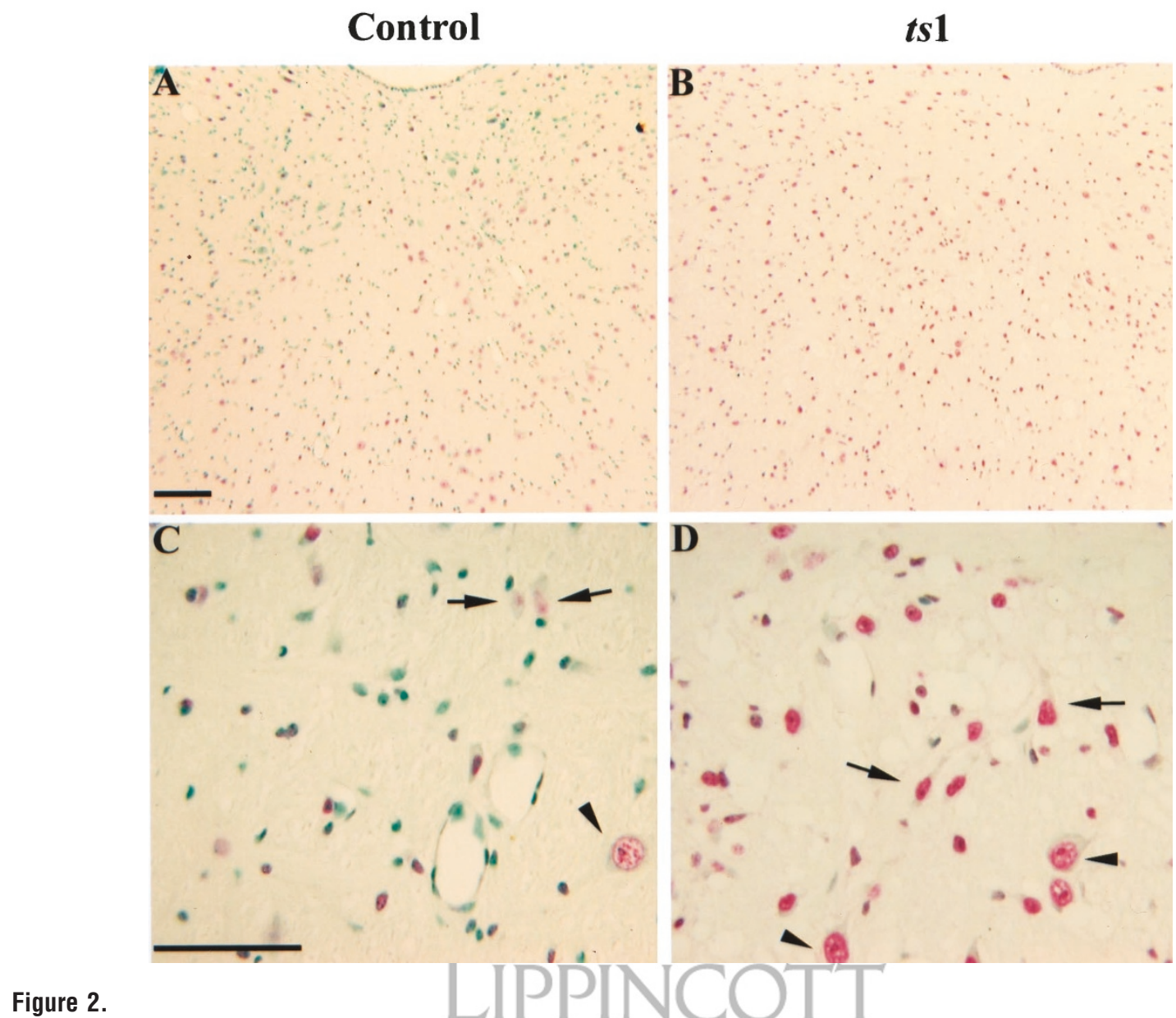

Expression of p53 protein in brain stem glial cells of control and ts1-infected mice at $25 \mathrm{dpi}$. A, p53 immunoreactivity (red) in the nuclei of brain stem glial cells and neurons from a control mouse. B, p53 immunnoreactivity in the nuclei of glial cells and neurons of the $t s 1$-infected mouse brain stem tissue. C, Higher magnification view of the glial and neuronal cells in panel A. Note the absent or weak nuclear staining in astrocytes (arrow) and neurons (arrowhead). D, Higher magnification views of the glial and neuronal cells in panel B, Note the strong staining in astrocytes (arrow) and neurons (arrowhead). Bars indicate $50 \mu \mathrm{m}$.

A

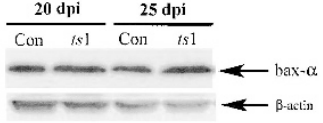

Figure 3.

Changes in bax- $\alpha$ protein level in brain stem homogenates of $t s 1$-infected mice. A, Increased abundance of bax- $\alpha$ protein in brain stem homogenates of ts 1 -infected mice. At 20 and $25 \mathrm{dpi}$, tissue homogenates were prepared from the brain stem of control and ts1-infected mice, and tissue homogenates (20 $\mu \mathrm{g}$ ) were then subjected to immunoblot analysis. B, Relative increases in the level of bax- $\alpha$ protein in the brain stem of $t s 1$-infected mice. Protein levels for bands were compared by densitometric analysis. At 20 and $25 \mathrm{dpi}$, the levels of bax- $\alpha$ protein in the brain stem of $t s 1$-infected mice were increased $18.5 \%$ $\pm 9.4 \%$ and $22.1 \% \pm 7.8 \%$, respectively, over levels in control mice $(p<$ $0.05)$. The results represented in the histogram are the mean \pm SE from tissues from three control and three $t s 1$-infected mice.

stem tissues, immunostaining for bax- $\alpha$ was performed (Fig. 4). No immunoreactivity was evident in brain stem neurons of control mice, and expression was absent or weak in a few glial cells in these mice (Fig. 4, A and C). However, glial cells including astro- cytes scattered throughout affected areas in ts 1 infected mice showed strong cytoplasmic staining (Fig. 4, B and D).

\section{Drized USE}

Increased Expression of p53 and Its Responsive Genes, bax-a and p21, in ts 1-Infected C1 Astrocytes

To determine whether p53 protein also accumulates in ts1-infected $\mathrm{C} 1$ astrocytes, the level of p53 protein was determined. Figure 5 ( $A$ and $B$ ) shows that the level of p53 protein was increased in infected cells, relative to mock-infected controls at 24,48 , and 72 hours after infection $(p<0.01)$. In both mock-infected and ts 1 -infected astrocytes, the level of p53 protein decreased over time. To determine whether increased p53 levels might affect p53-responsive genes, we then examined the expression of bax- $\alpha$ and p21 in mockinfected and ts1-infected astrocytes by immunoblotting analysis. Figure 5 (C, D, E, and F) shows that the levels of bax- $\alpha$ and p21 protein in ts 1 -infected C1 astrocytes were higher than those in the mockinfected astrocytes at 24 and 48 hours after infection $(p<0.01)$. 
Control
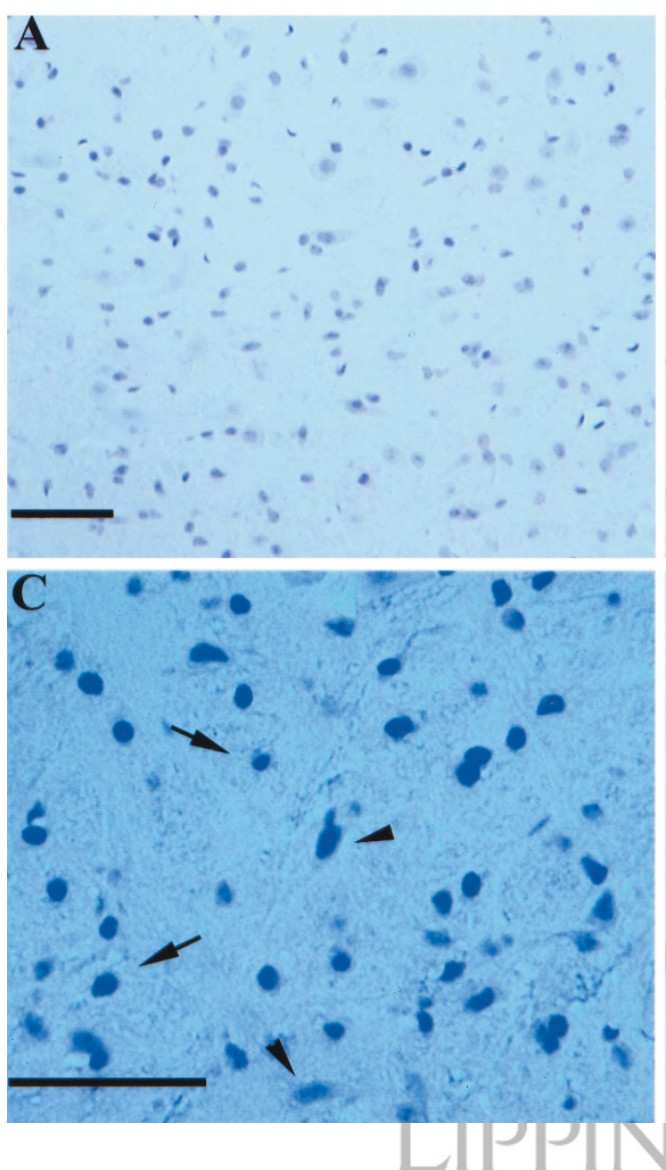

ts1
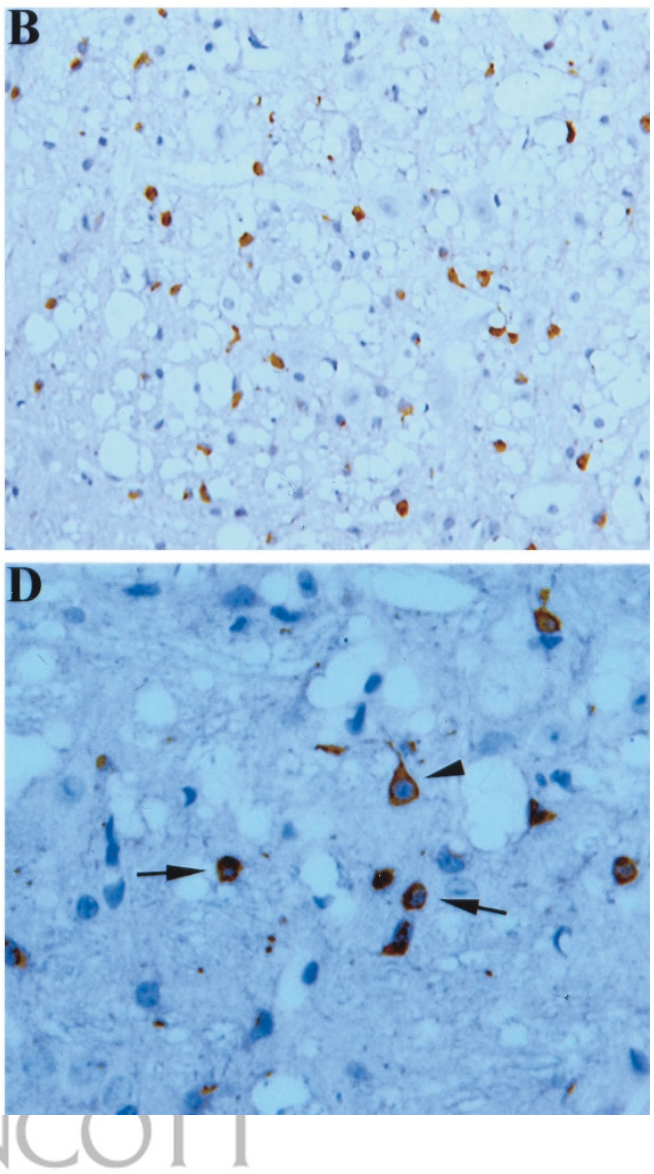

Figure 4.

Localization of bax- $\alpha$ in brain stem glial cells of control and ts1-infected mice at $25 \mathrm{dpi}$. A. Cytoplasmic bax- $\alpha$ immunoreactivity (brown) in brain stem glial cells of a control mouse. B, Cytoplasmic bax - $\alpha$ immunoreactivity in brain stem glial cells of $t s 1$-infected mouse. C, Higher măgnification view of the glial and neuronal cells in panel A. Note the weak cytoplasmic staining in astrocytes (arrow) and neurons (arrowhead). D. Higher magnification view of the glial and neuronal cells in panel B. Note the strong cytoplasmic staining in astrocytes (arrow) and neurons (arrowhead). Bars indicate $50 \mu \mathrm{m}$.

\section{Normal Degradation of p53 in ts1-Infected C1 Astrocytes by the Calpain and Ubiquitin-Proteasome Pathways}

To determine how proteolytic pathways involved in p53 degradation might be affected after ts 1 infection, we measured the p53 level in mock-infected and ts1-infected $\mathrm{C} 1$ astrocytes after treatment with calpeptin, a specific calpain inhibitor, or MG-132, a potent proteasome inhibitor. Figure 6 shows that both agents caused increases in the level of p53 protein compared with ts1-infected cells without treatment. MG-132 also increased the level of p53 protein in mock-infected cells $(p<0.01)$, but calpeptin did not. These results indicate that these two proteolytic pathways are active in the degradation of p53 in ts 1 infected cells.

\section{Activation of ERK in C1 Astrocytes by ts 1 Infection and Blockade of ts 1 Infection-Induced p53 Accumulation by Inhibition of ERK Activity}

Both ERKs and p38 kinase seem to participate in stabilization of p53 protein. To determine whether ERK or p38 kinase activity is altered after ts 1 infection, we assessed the phosphorylation status of ERK 1/2 and p38 kinase in mock-infected and ts 1 -infected $\mathrm{C} 1$ cells. Figure 7A shows that phosphorylated ERK1/2 levels were increased after ts 1 infection, whereas phosphorylated p38 kinase level is unchanged. Also, to determine whether accumulation of p53 requires similar changes in ERKs or p38 kinase, we used two specific inhibitors to inactivate ERK and p38 kinases. PD98059, a specific inhibitor of MEK1, acts by inhibiting activation of ERKs. SB202190 is a specific inhibitor of p38 kinase. Both were tested for their activity to modify ts 1 infection-mediated p53 accumulation. Figure 7B shows that treatment with $20 \mu \mathrm{M}$ of PD98059 decreased the level of p53 in parallel with decreases in the level of phosphorylated ERKs and in expression of p21, a p53-dependent gene. By contrast, treatment with $10 \mu \mathrm{M}$ of SB202190 did not inhibit p53 accumulation in ts1-infected C1 astrocytes. These data pinpoint ERKs as upstream modifiers of p53 accumulation in ts1-infected $\mathrm{C} 1$ astrocytes.

\section{Discussion}

The data clearly indicate that MoMuLV-ts 1 infection increases the expression and accumulation of p53 
A

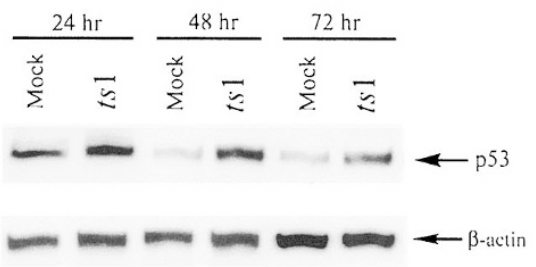

C

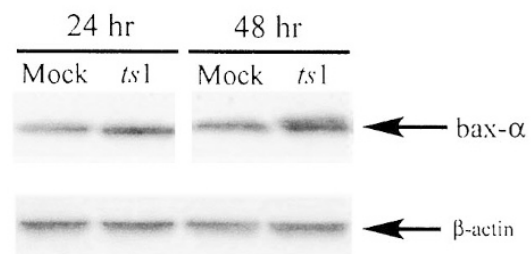

E

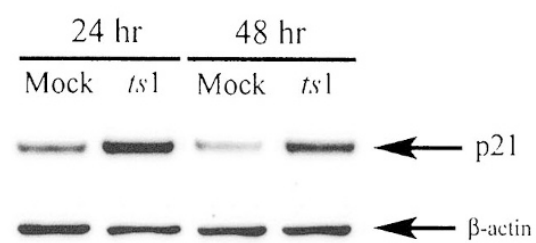

B
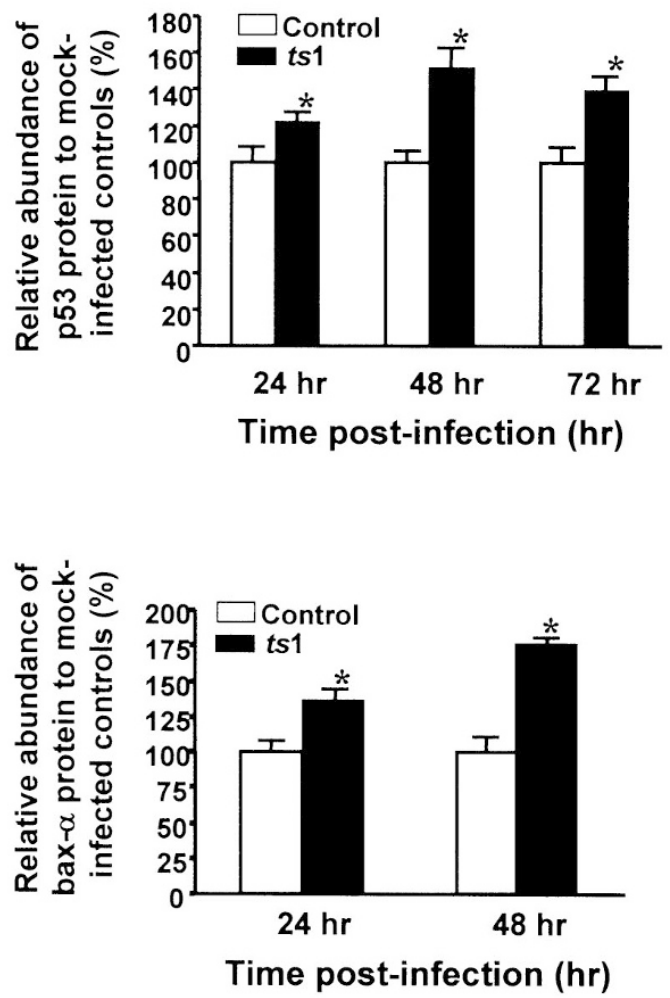

F

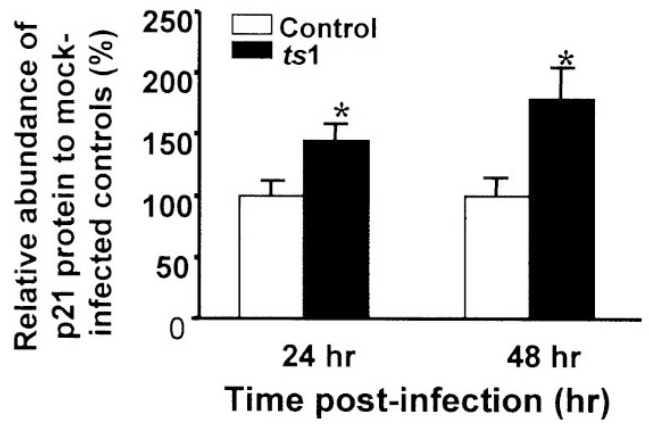

\section{Figure 5.}

ts 1 infection induced increases in the level of p53, bax- $\alpha$, and p21 protein in C1 astrocytes. A, Time course of p53 expression in C1 astrocytes after ts 1 infection. $\mathrm{C} 1$ astrocytes were mock or $t s 1$ infected and whole cell lysates prepared at 24,48 , and 72 hours after infection for immunoblotting. B, Relative increases in the level of p53 protein in $t s 1$-infected $\mathrm{C} 1$ astrocytes. The protein level was expressed relative to that in controls at each time point to compare ts 1 infection-induced changes in the level using data obtained from densitometric analysis of autoradiographs. C, Time course of bax- $\alpha$ expression in C1 astrocytes after ts 1 infection. C1 astrocytes were mock or $t s 1$ infected and whole cell lysates prepared at 24 and 48 hours after infection for immunoblotting. D, Relative increases in the level of bax- $\alpha$ protein in ts 1 -infected $\mathrm{C} 1$ astrocytes. E, Time course of $\mathrm{p} 21$ expression in $\mathrm{C} 1$ astrocytes after ts 1 infection. C1 astrocytes were mock or ts 1 infected and whole cell lysates prepared at 24 and 48 hours after infection for immunoblotting. F, Relative increases in the level of p21 protein in ts1-infected C1 astrocytes. The protein level was expressed relative to that in controls at each time point to compare $t s 1$ infection-induced changes in the level using data obtained from densitometric analysis of autoradiographs. The results are the mean \pm SD from three independent experiments carried out in triplicate $(n=9)$ and are representative of those from three independent experiments. ${ }^{\star}$ Significantly different from controls $(p<0.01)$.

protein and its dependent genes in astrocytes. Overexpression of p53 and bax- $\alpha$ is known to lead to cell cycle arrest or apoptosis (Haffner and Oren, 1995; Levine 1997; Liu et al, 1994; Miyashita and Reed,
1995), but whether the two events also occur in the brain stem of ts 1 -infected mice remains to be determined because most bax- $\alpha$ immunoreactive glial cells in brain stem lesions do not have the characteristic 
A

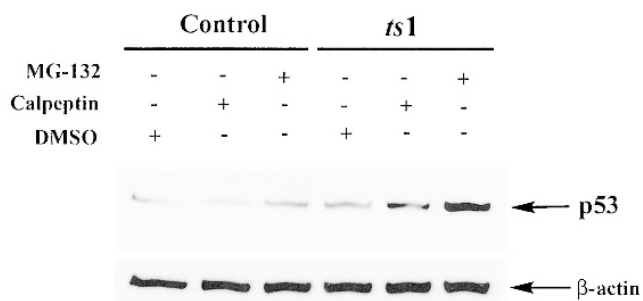

B

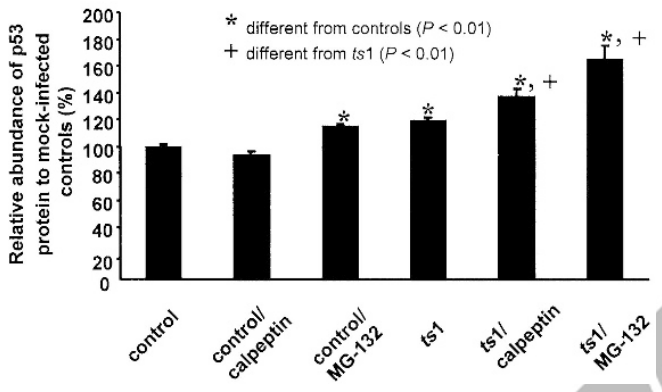

Figure 6.

Proteolytic pathways involved in p53 degradation in C1 astrocytes. A, Effects of calpain and proteasome inhibitors on degradation of p53 proteins in ts 1 -infected $\mathrm{C} 1$ astrocytes. At 48 hours after infection, C1 astrocytes were treated with various protease inhibitors for 4 hours before cell tysate preparation. Whole cell lysates (20 $\mu \mathrm{g}$ of protein) were then separated by SDS-PAGE and analyzed by immunoblotting. B, Accumulation of $p 53$ protein in ts 1 -infected $\mathrm{C} 1$ astrocytes after treatment with either MG-132, a proteasome inhibitor, or calpeptin, a calpain inhibitor. Compared with cells infected with $t s 1$ alone, p53 protein proteolysis was significantly blocked in ts 1 -infected $\mathrm{C1}$ astrocytes by treatment with MG-132 $(54.3 \% \pm 9.1 \%)$. ${ }^{*}$ Significantly different from controls $(p<0.01)$; + significantly different from ts 1 infection alone (dimethyl sulfoxide; $p<0.01$ ). The results are the mean \pm sD from three independent experiments carried out in triplicate $(n=9)$ and are representative of those from three independent experiments.
A
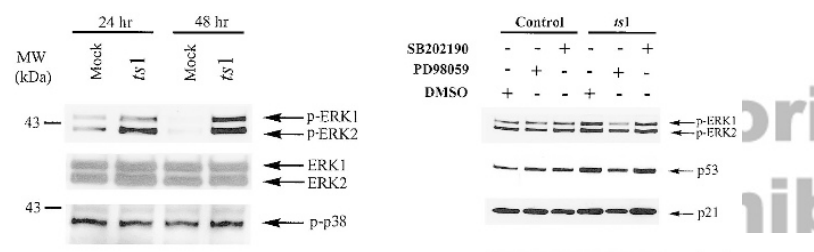

sible that there is counteracting regulation of specific antiapoptotic molecules such as bcl-2 or bcl- $\mathrm{X}_{\mathrm{L}}$. Recent reports suggest that bax- $\alpha$-induced cell death is different from typical apoptotic processes, involving interference with mitochondrial functions and generation of reactive oxygen species (Pastorino et al, 1998; Xiang et al, 1996). Although the activities of the bcl-2/bax- $\alpha$ family are unclear in this model, they may be central to our understanding of this important aspect of ts1-mediated pathogenesis.

To examine changes in the level of p53 protein after ts 1 infection and how ts 1 affects p53 levels in astrocytes, we used a well-defined in vitro system. We first determined whether two well-known proteolytic pathways for p53, the ubiquitin-proteasome pathway (Kubbutat et al, 1997; Maki et al, 1996) and the calpain pathway (Pariat et al, 1997), are functional in ts1infected $\mathrm{C} 1$ astrocytes. The data suggest that the ubiquitin-proteasome pathway plays the dominant role in the degradation of p53 in both mock-infected and $t$ 1-infected $\mathrm{C} 1$ cells and that this pathway remains functional after ts 1 infection. Interestingly the calpain pathway participates in p53 degradation in ts1-infected C1 astrocytes but not in mock-infected cells. This is consistent with our previous observations showing no significant changes in ubiquitinconjugating activity but activation of the calpain pathway in ts1-infected C1 astrocytes (Kim et al, 2001). The increased p53 in ts1-infected C1 astrocytes apparently is not a consequence of proteasome malfunction.

p53 accumulation after ts 1 infection is accompanied by increased ERK1/2 activity. ERK1/2 activation is inhibited by PD98059, a synthetic inhibitor of MEK1 (the immediate upstream kinase of ERK1/2) that prevents activation of MAPK and subsequent phosphorylation of MAPK substrates (Alessi et al, 1995; Dudley et al, 1995). Inhibition of ts1-induced ERK1/2 activation by PD98059 decreased p53 accumulation and p53 function, as demonstrated by a lower level of the p53-dependent p21WAF-1. These findings indicate that ERK1/2 activation is required for maximum accumulation and activation of p53 in ts1-infected C1 astrocytes. Decreased accumulation of p53 could conceivably be secondary to a shorter protein half-life; however, because PD98059 does not completely inhibit accumulation of p53 protein, additional upstream signaling pathways may contribute to the stability of p53 after ts 1 infection.

The mechanisms responsible for the activation of ERKs in ts 1-infected astrocytes may be diverse. One potential mechanism is that multiple $\mathrm{Ca}^{2+}$-dependent $\mathrm{PKC}$ isoforms may participate in ERK activation after ts 1 infection as supported by a recent report (Monick et al, 2001) and our preliminary results (data not shown). Another mechanisms may be initiated by the endoplasmic reticulum (ER). Specially, the viral envelope protein plays an important role in both HIV- and ts1-mediated neuropathology. A single mutation in the ts 1 env gene results in a protein called gPr $80^{\mathrm{env}}$, which is inefficiently processed and transported to the plasma membrane of infected astrocytes and $\mathrm{T}$ cells, 
leading to accumulation of $\mathrm{gPr} 80^{\text {env }}$ protein in the ER. In a previous study, we showed that the cytopathic effects of ts 1 on primary astrocytes in vitro closely correlated with the accumulation of ts 1 precursor envelope protein in the ER (Shikova et al, 1993). Therefore, the ER may be the primary intracellular organelle in which ts 1 envelope protein-mediated signaling pathways responsible for ERK activation are generated. Several studies have demonstrated that alterations in protein folding and/or trafficking through the ER could activate PKR-like ER kinase (PERK) and protein kinase RNA-regulated (PKR) (Iwawaki et al, 2001; Kaufman, 1999), which in turn activate downstream mediators such as ERKs, leading to the observation that we detected in the present study.

The JNK and p38 kinase pathways are associated with increased apoptosis, whereas the ERK pathway has been shown to suppress apoptosis (Xia et al, 1995). Increased expression of upstream activators of p38 kinase and JNK such as apoptosis signalregulating kinase 1 (ASK1) (Ichijo et al, 1997) and MAP kinase kinase kinase 1 (MEKK1) (Fuchs et al, 1998b) also triggers apoptosis. Therefore, specific activation of astrocyte ERKs may be a positive response to viral infection. Alternatively, phosphorylation of ERKs may be related to both induction of apoptosis and proliferation of astrocytes (Neary et al, 1998). It was recently reported that activation of ERK also regulates the expression of inducible nitric oxide synthase in astrocytes (Bhat et al, 1998). Together these observations show that the outcome of ERK activation in ts1infected astrocytes is complex. We suspect that "bystander" effects of the activated MAPK pathway caused by ts 1 infection could exert additional effects on astrocytes themselves or surrounding neurons.

Additionally, p53 protein plays a critical role in cellular response to environmental stress. Activation of p53 protein in response to stress involves posttranslational modification of the protein, including specific phosphorylation at serine residues within the $\mathrm{N}$-terminal transactivation domain (Fuchs et al, 1998a; Giaccia and Kastan, 1998). Recently, other members of the MAP kinase family, including JNK and p38 kinase, have also been shown to phosphorylate p53 protein (Fuchs et al, 1998a; She et al, 2000). Activated JNK phosphorylates mouse p53, thereby affecting MDM2 binding to p53 (Fuchs et al, 1998b). This supports the idea that different upstream signal transducers activate p53 in response to different forms of cellular stress. Further analysis will be required to identify specific amino acids phosphorylated on p53 after activation of ERKs in ts1-infected astrocytes.

In conclusion, the data reported here show that the brain stem neuropathology of MoMuLV-ts1 infection involves changes in p53 protein levels and bax- $\alpha$ expression in astrocytes. They also suggest that p53 is accumulated in ts1-infected astrocytes as a consequence of ERK activation in vitro and that this results in expression of p53-dependent genes. Our results have possible implications for other retrovirus-induced neurodegeneration in animals and humans.

\section{Materials and Methods}

Sodium orthovanadate $\left(\mathrm{Na}_{3} \mathrm{VO}_{4}\right)$, sodium $\beta$-glycerophosphate, sodium fluoride ( $\mathrm{NaF})$, dithiothreitol, and phenylmethylsulfonyl fluoride were purchased from Sigma Chemical Company (St. Louis, Missouri). Leupeptin, pepstatin, and aprotinin were purchased from Boehringer Mannheim (Indianapolis, Indiana). lodoacetamide (an isopeptidase inhibitor) was obtained from Fluka Chemical Corp. (Milwaukee, Wisconsin). Phospho-specific ERK1/2 and p38 kinase antibodies, ERK1/2 antibody, and p38 kinase antibody were purchased from New England BioLabs (Beverly, Massachusetts). Monoclonal mouse IgG antibody against p53 (antibody-1) was obtained from Oncogene Research Products (Cambridge, Massachusetts). Polyclonal rabbit IgG antibody against bax- $\alpha$ (SC-526) and polyclonal rabbit IgG antibody against p21 (SC-471) were purchased from Santa Cruz Biotechnology (Santa Cruz, California). Monoclonal mouse IgG antibody against $\beta$-actin (A5441) was purchased from Sigma. A MEK1-specific inhibitor, PD98059, and a p38 kinase inhibitor, SB202190, were obtained from Calbiochem (San Diego, California). DMEM and fetal bovine serum (FBS) were obtained from Life Technologies, Inc. (Rockville, Maryland). PD98059, SB202190, MG-132, and calpeptin were dissolved in dimethyl sulfoxide and stored at $-80^{\circ} \mathrm{C}$.

\section{Virus}

ts 1 , a spontaneous temperature-sensitive mutant of MoMuLV, was propagated in TB cells, a thymus-bone marrow cell line. Virus titers were determined using a modified direct focus assay in the $15 \mathrm{~F}$ cell line, a murine sarcoma-positive, leukemia-negative cell line, as described previously (Wong et al, 1981).

\section{Animals and Virus Inoculation}

FVB/N mice were obtained from Taconic Farms (Germantown, New York). Mice were maintained in sterilized microisolators and supplied with autoclaved food and water ad libitum. Newborn FVB/N mice were inoculated intraperitoneally with $0.1 \mathrm{ml}$ of $t \mathrm{~s} 1$ viral suspension containing $10^{6}$ to $10^{7}$ infection units $/ \mathrm{ml}$, as described previously (Stoica et al, 2000); control mice were inoculated with medium only. The mice were then observed daily for clinical signs of disease and killed at $25 \mathrm{dpi}$. The experimental protocol was approved by the Texas A\&M University Institutional Animal Care and Use Committee.

\section{Tissue Preparation}

For histopathology and immunohistochemistry studies, ts1-infected $(n=5)$ and control $(n=5)$ mice were anesthetized using an intraperitoneal injection of pentobarbital $(150 \mathrm{mg} / \mathrm{kg}$ ) and transcardially perfused with $10 \%$ buffered formalin as a fixative, using a peristaltic pump. After 12 hours of fixation, each mouse's brain was dissected, with the brain stem segments separated for further processing. For Western immunoblotting analysis 
of p53 and bax- $\alpha$ protein in the brain stem, ts 1 -infected $(n=3)$ and control $(n=3)$ mice were killed and their brains were dissected; brain stem tissues were snapfrozen in liquid nitrogen and stored at $-80^{\circ} \mathrm{C}$.

\section{Immunohistochemistry}

Immunohistochemistry was performed to localize p53 and bax- $\alpha$ protein on brain stem tissue sections. Briefly, paraffin-embedded sections $(6 \mu \mathrm{m})$ were deparaffinized and washed with $0.4 \%$ Triton X-100 in Tris-buffered saline (100 mm Tris, $150 \mathrm{~mm} \mathrm{NaCl}, \mathrm{pH}$ 7.4) for 20 minutes at room temperature. Potential nonspecific binding sites were blocked with $2 \%$ bovine serum albumin, after which the tissue sections were incubated with either monoclonal anti-p53 antibody or rabbit anti-bax- $\alpha$ antibody at a dilution of 1:100 $(2.0 \mu \mathrm{g} / \mathrm{ml})$ for 2 hours. After three 5-minute washes in Tris-buffered saline, sections were incubated with biotin-conjugated secondary antimouse or anti-rabbit lgG (Pierce, Rockford, Illinois) for 30 minutes at room temperature. Either a Vectastain ABCalkaline phosphatase kit (Vector Laboratories, Burlingame, California) or a Vecta-Elite streptavidinperoxidase kit with a benzidine substrate was used for color development. Sections were counterstained with $1 \%$ methyl green or diluted hematoxylin. Sections that were not incubated with a primary antibody served as negative controls.

\section{Cell Culture and Virus Infection}

Immortalized murine $\mathrm{C} 1$ astrocytes were maintained in DMEM supplemented with $10 \%$ FBS and antibiotics (100 U/ml penicillin and $100 \mu \mathrm{g} / \mathrm{ml}$ streptomycin) (Lin et al, 1997). All cells were grown at $37^{\circ} \mathrm{C}$ in a humidified incubator containing $5 \% \mathrm{CO}_{2}$. Cells were passaged biweekly and used for experiments while in the exponential growth phase. For virus infection, $\mathrm{C} 1$ cells $(4 \times 10$ 5) in DMEM containing $2 \%$ FBS and $4 \mu \mathrm{g} / \mathrm{ml}$ polybrene were seeded in $100-\mathrm{mm}$ tissue culture dishes. After culturing overnight, the medium was removed; the cells were infected with $t s 1$ virus at a multiplicity of infection of 10 in DMEM containing $2 \%$ FBS and $4 \mu \mathrm{g} / \mathrm{ml}$ polybrene and incubated for 1 hour at $37^{\circ} \mathrm{C}$ under $5 \% \mathrm{CO}_{2}$. After virus adsorption, the medium containing the virus was removed and DMEM containing 2\% FBS added to the culture. The plates were then incubated for various times at $38.5^{\circ} \mathrm{C}$ (Lin et al, 1997). For mock infection, C1 astrocytes were treated identically, except that the medium used was DMEM containing polybrene only. For studies of proteasome and calpain proteolysis inhibition, MG-132 $(20 \mu \mathrm{M})$, calpeptin $(20 \mu \mathrm{M})$, or dimethyl sulfoxide only (less than $0.1 \%$ ) was added to the culture medium of ts 1 -infected and mock-infected cells, and the cells were incubated for an additional 4 hours before cell lysate preparation, as described previously (Kim et al, 2001). For studies of MAPK inhibition, PD98059 $(20 \mu \mathrm{M})$, SB202190 $(10 \mu \mathrm{M})$, or dimethyl sulfoxide only (less than $0.1 \%$ ) was added to the culture medium of $t s 1$-infected and mock-infected cells at 4 hours postinfection, and the cells were incubated for an additional 16 hours before cell lysate preparation.

\section{Tissue and Cell Extracts}

Brain stem tissue lysates were prepared by homogenization of frozen tissues in 10 volumes of lysis buffer containing $50 \mathrm{~mm}$ Tris- $\mathrm{HCl}(\mathrm{pH} 7.9), 150 \mathrm{~mm} \mathrm{NaCl}, 1 \mathrm{~mm}$ EDTA, $1 \mathrm{~mm} \mathrm{Na} \mathrm{VO}_{4}, 30 \mathrm{~mm}$ sodium $\beta$-glycerophosphate, $50 \mathrm{~mm} \mathrm{NaF}, 10 \mathrm{~mm}$ iodoacetamide, $1 \mathrm{~mm}$ dithiothreitol, $1 \%$ NP-40, $1 \mathrm{~mm}$ phenylmethylsulfonyl fluoride, $10 \mu \mathrm{g} / \mathrm{ml}$ pepstatin, $10 \mu \mathrm{g} / \mathrm{ml}$ leupeptin, and 5 $\mu \mathrm{g} / \mathrm{ml}$ aprotinin. Lysates were cleared by centrifugation at $13,000 \times g$ at $4^{\circ} \mathrm{C}$ for 20 minutes and the resulting supernatants frozen at $-80^{\circ} \mathrm{C}$. Also, whole cell extracts from $\mathrm{C} 1$ cells were prepared as follows. Briefly, cells were washed twice with cold phosphate-buffered saline $(\mathrm{pH}$ 7.4) and lysed in lysis buffer. After incubation on ice for 15 minutes, the cell lysates were cleared by centrifugation at $13,000 \times g$ for 20 minutes at $4^{\circ} \mathrm{C}$ and the supernatants kept frozen at $-80^{\circ} \mathrm{C}$. The protein content of the lysates was determined using the Bradford assay (Bio-Rad, Hercules, California), with bovine serum albumin as the standard.

\section{Western Immunoblotting Analysis}

Proteins $(20 \mu \mathrm{g})$ were separated by $8 \%$ to $12 \%$ SDS-PAGE and then transferred to nitrocellulose membranes (Schleicher \& Schuell, Keene, New Hampshire). Kaleidoscope prestained standards (Bio-Rad) were used to determine molecular weight. The membranes were incubated for 1 hour in blocking buffer (20 $\mathrm{mm}$ Tris- $\mathrm{HCl}$-buffered saline containing $5 \%$ nonfat milk powder and $0.1 \%$ Tween 20 ) at room temperature and then probed with appropriate antibodies in $20 \mathrm{~mm}$ Tris- $\mathrm{HCl}$-buffered saline containing $2 \%$ nonfat milk powder and $0.1 \%$ Tween 20 overnight at $4^{\circ} \mathrm{C}$. Normal mouse or rabbit IgGs at the same dilutions were used as controls. The blots were then incubated with antimouse or anti-rabbit IgG-peroxidase conjugate (1:10,000 dilution; Kirkegaard Perry Laboratories, Gaithersburg, Maryland) and developed using the enhanced chemiluminescence method (Amersham Life Science, Arlington Heights, Illinois). After stripping, the blots were then incubated with a mouse monoclonal anti- $\beta$-actin antibody to confirm equal protein loading and normalize the loading. Densitometric analysis of autoradiographs was performed using a densitometer (Model GS-690; Bio-Rad) equipped with the MultiAnalyst software program (version 1.01; Bio-Rad).

\section{Statistical Analysis}

Data obtained from densitometric analysis of Western immunoblots were analyzed by paired $t$ test or ANOVA. Additionally, statistical significance between groups was determined by Dunnett's multiple comparison analysis. $P$ values $<0.05$ were considered statistically significant.

\section{Acknowledgements}

We are grateful to Ms. Virginia Scoffield and Mr. Don Norwood for critical comments on the manuscript. 


\section{References}

Akagi T, Ono H, and Shimotohno K (1996). Expression of cell-cycle regulatory genes in HTLV-I infected T-cell lines: Possible involvement of Tax 1 in the altered expression of cyclin D2, p18ink4 and p21waf1/cip1/sdi1. Oncogene 12: 1645-1652.

Alessi DR, Cuenda A, Cohen P, Dudley DT, and Saltiel P (1995). PD 098059 is a specific inhibitor of the activation of mitogen-activated protein kinase in vitro and in vivo. $\mathrm{J}$ Biol Chem 270:27489-27494.

Bhat NR, Zhang P, Lee JC, and Hogan EL (1998). Extracellular signal-regulated kinase and p38 subgroups of mitogenactivated protein kinases regulate inducible nitric oxide synthase and tumor necrosis factor-alpha gene expression in endotoxin-stimulated primary glial cultures. J Neurosci 18: 1633- 1641.

Cereseto A, Diella F, Mulloy JC, Cara A, Michieli P, Grassmann R, Franchini G, and Klotman ME (1996). p53 functional impairment and high p21 (waf1/cip1) expression in human T-cell lymphotropic/leukemia virus type I-transformed T cells. Blood 88:1551-1560.

Choe W, Stoica G, Lynn W, and Wong PKY (1998). Neurodegeneration induced by MoMuLV-ts1 and increased expression of Fas and TNF- $\alpha$ in the central nervous system. Brain Res 779:1-8.

Chretien F, Boche D, Lorin de la Grandmaison G, Ereau T, Mikol J, Hurtrel M, Hurtrel B, and Gray F (2000). Progressive multifocal leukoencephalopathy and oligodendroglioma in a monkey co-infected by simian immunodeficiency virus and simian virus 40. Acta Neuropathol (Berl) 100:332-336.

Dhanasekaran N and Reddy EP (1998). Signaling by dūal specificity kinases. Oncogene 17:1447-1455.

Dudley DT, Pang L, Decker SJ, Bridges AJ, and Salteil AR (1995). A synthetic inhibitor of the mitogen-activated protein kinase cascade. Proc Natl Acad Sci USA 92:7686-7689.

Ehsan A, Fan H, Eagan PA, Siddiqui HA, and Gulley ML (2000). Accumulation of p53 in infectious mononucleosis tissues. Hum Pathol 31:1397-1403.

Fuchs SY, Adler V, Pincus MR, and Ronai Z (1998a). MEKK1/ JNK signaling stabilizes and activates p53. Proc Natl Acad Sci USA 95:10541-10546.

Fuchs SY, Fried VA, and Ronai Z (1998b). Stress-activated kinases regulate protein stability. Oncogene 17:1483-1490.

Gardner MB (1978). Type C viruses of wild mice: Characterization and natural history of amphotropic, ecotropic, and xenotropic MuLV. Curr Top Microbiol Immunol 79:215-259.

Genini D, Sheeter D, Rought S, Zaunders JJ, Susin SA, Kroemer G, Richman DD, Carson DA, Corbeil J, and Leoni LM (2001). HIV induces lymphocyte apoptosis by a p53-initiated, mitochondrial-mediated mechanism. FASEB J 15:5-6.

Giaccia AJ and Kastan MB (1998). The complexity of p53 modulation: Emerging patterns from divergent signals. Genes Dev 12:2973-2983.

Haffner R and Oren M (1995). Biochemical properties and biological effects of p53. Curr Opin Genet Dev 5:84-90.

Haupt Y, Maya R, Kazaz A, and Oren M (1997). Mdm2 promotes the rapid degradation of p53. Nature 387:296-299.

Ichijo H, Nishida E, Irie K, ten Dijke P, Saitoh M, Moriguchi T, Takagi M, Matsumoto K, Miyazono K, and Gotoh Y (1997).
Induction of apoptosis by ASK1, a mammalian MAPKKK that activates SAPK/JNK and p38 signaling pathways. Science 275:90-94.

Iwawaki T, Hosoda A, Okuda T, Kamigori Y, NomuraFuruwatari C, Kimata Y, Tsuru A, and Kohno K (2001). Translational control by the ER transmembrane kinase/ ribonuclease IRE1 under ER stress. Nat Cell Biol 3:158-164.

Jordan-Sciutto KL, Wang G, Murphy-Corb M, and Wiley CA (2000). Induction of cell-cycle regulators in simian immunodeficiency virus encephalitis. Am J Pathol 157:497-507.

Kaufman RJ (1999). Stress signaling from the lumen of the endoplasmic reticulum: Coordination of gene transcriptional and translational controls. Genes Dev 13:1211-1233.

Keller D, Zeng X, Li X, Kapoor M, lordanov MS, Taya Y, Lozano G, Magun B, and Lu H (1999). The p38MAPK inhibitor SB203580 alleviates ultraviolet-induced phosphorylation at serine 389 but not serine 15 and activation of p53. Biochem Biophys Res Commun 261:464-471.

Kim HT, Qiang W, Wong PKY, and Stoica G (2001). Enhanced proteolysis of $I_{\kappa} \mathrm{B} \alpha$ and $I_{\kappa} \mathrm{B} \beta$ proteins in astrocytes by Moloney murine leukemia virus (MoMuLV)-ts1 infection: A potential mechanism of NF- $\kappa$ B activation. J Neurovirol 7:466-475.

Kubbutat MH, Jones SN, and Vousden KH (1997). Regulation of p53 stability by Mdm2. Nature 387:299-303.

Levine AJ (1997). p53, the cellular gatekeeper for growth and division. Cell 88:323-331.

Lewis TS, Shapiro PS, and Ahn NG (1998). Signal transduction through MAP kinase cascades. Adv Cancer Res 74:49-139.

Lin YC, Chow CW, Yuen PH, and Wong PKY (1997). Establishment and characterization of conditionally immortalized astrocytes to study their interaction with ts1, a neuropathogenic mutant of Moloney murine leukemia virus. J Neurovirol 3:8-37.

Liu M, Dhanwada KR, Birt DF, Hecht S, and Pelling JC (1994) Increase in $\mathrm{p} 53$ protein half-life in mouse keratinocytes following UV-B irradiation. Carcinogenesis 15:1089-1092.

Maki CG, Huibregtse JM, and Howley PM (1996). In vivo ubiquitination and proteasome-mediated degradation of p53. Cancer Res 56:2649-2654.

McLean TI and Bachenheimer SL (1999). Activation of C-Jun $\mathrm{N}$-terminal kinase by herpes simplex virus type 1 enhances viral replication. J Virol 73:8415-8426.

Miyashita T and Reed JC (1995). Tumor suppressor p53 is a direct transcriptional activator of the human bax gene. Cell 80:293-299.

Monick MM, Staber JM, Thomas KW, and Hunninghake GW (2001). Respiratory syncytial virus infection results in activation of multiple protein kinase $C$ isoforms leading to activation of mitogen-activated protein kinase. J Immunol 166:2681-2687.

Mosner J, Mummenbrauer T, Bauer C, Sczakiel G, Grosse F, and Deppert W (1995). Negative feedback regulation of wild-type p53 biosynthesis. EMBO J 14:4442-4449.

Neary JT, McCarthy M, Kang Y, and Zuniga S (1998). Mitogenic signaling from $\mathrm{P} 1$ and $\mathrm{P} 2$ purinergic receptors to mitogen-activated protein kinase in human fetal astrocyte cultures. Neurosci Lett 242:159-162.

Pariat M, Carillo S, Molinari M, Salvat C, Debussche L, Bracco L, Milner J, and Piechaczyk M (1997). Proteolysis by calpains: A possible contribution to degradation of p53. Mol Cell Biol 17:2806-2815. 
Pastorino JG, Chen ST, Tafani M, Snyder JW, and Farber JL (1998). The overexpression of Bax produces cell death upon induction of the mitochondrial permeability transition. J Biol Chem 273:7770-7775.

Persons DL, Yazlovitskaya EM, and Pelling JC (2000). Effect of extracellular signal-regulated kinase on p53 accumulation in response to cisplatin. J Biol Chem 275:35778-35785.

Peters RL, Spahn GJ, Rabstein LS, Kelloff GJ, and Huebner RJ (1973). Murine C-type RNA virus from spontaneous neoplasms: In vitro host range and oncogenic potential. Science 181:665-667.

Popik W and Pitha PM (1998). Early activation of mitogenactivated protein kinase kinase, extracellular signal-regulated kinase, p38 mitogen-activated protein kinase, and c-Jun $\mathrm{N}$-terminal kinase in response to binding of simian immunodeficiency virus to Jurkat T cells expressing CCR5 receptor. Virology 252:210-217.

Robinson MJ and Cobb MH (1997). Mitogen-activated protein kinase pathways. Curr Opin Cell Biol 9:180-186.

Roulston A, Marcellus RC, and Branton PE (1999). Viruses and apoptosis. Annu Rev Microbiol 53:577-628.

She QB, Chen N, and Dong Z (2000). ERKs and p38 kinase phosphorylate p53 protein at serine 15 in response to UV radiation. J Biol Chem 275:20444-20449.

Shieh SY, Ikeda M, Taya Y, and Prives C (1997). DNA damage-induced phosphorylation of p53 alleviates inhibition by MDM2. Cell 91:325-334.

Shikova E, Lin YC, Saha K, Brooks BR, and Wong PKY (1993). Correlation of specific virus-astrocyte interactions and cytopathic effects induced by ts 1 , a neurovirulent mutant of Moloney murine leukemia virus. J Virol 67:1137-1147.

Siliciano JD, Canman CE, Taya Y, Sakaguchi K, Appella E, and Kastan MB (1997). DNA damage induces phosphorylation of the amino terminus of p53. Genes Dev 11:3471-34 81 . Song X, Bishop JE, Okamura WH, and Norman AW (1998). Stimulation of phosphorylation of mitogen-activated protein kinase by 1alpha,25-dihydroxyvitamin D3 in promyelocytic NB4 leukemia cells: A structure-function study. Endocrinology 139:457-465.

Stoica G, Illanes O, Tasca SI, and Wong PKY (1993). Tem poral central and peripheral nervous system changes induced by a paralytogenic mutant of Moloney murine leukemia virus TB. Lab Invest 69:724-735.

Stoica G, Tasca SI, and Wong PKY (2000). Motor neuronal loss and neurofilament-ubiquitin alteration in MoMuLV-ts1 encephalopathy. Acta Neuropathol (Berl) 99:238-244.

Storey A, Thomas M, Kalita A, Harwood C, Gardiol D, Mantovani F, Breuer J, Leigh IM, Matlashewski G, and Banks $L$ (1998). Role of a p53 polymorphism in the development of human papillomavirus-associated cancer. Nature 393:229234.
Sun X, Shimizu H, and Yamamoto K (1995). Identification of a novel p53 promoter element involved in genotoxic stressinducible p53 gene expression. Mol Cell Biol 15:4489-4996.

Szurek PF, Yuen PH, Ball JK, and Wong PK (1990). A Val-25-to-lle substitution in the envelope precursor polyprotein, gPr80env, is responsible for the temperature sensitivity, inefficient processing of gPr80env, and neurovirulence of ts1, a mutant of Moloney murine leukemia virus TB. J Virol 64:467-475.

Watanabe D, Honda T, Nishio K, Tomita Y, Sugiura Y, and Nishiyama $Y$ (2000). Corneal infection of herpes simplex virus type 2-induced neuronal apoptosis in the brain stem of mice with expression of tumor suppressor gene (p53) and transcription factors. Acta Neuropathol (Berl) 100:647-653.

Weitzman JB and Yaniv M (1998). Signal transduction pathways and modulation of gene activity. Clin Chem Lab Med 36:535-539.

Wong PKY, Floyd E, and Szurek PF (1991). High susceptibility of $\mathrm{FVB} / \mathrm{N}$ mice to the paralytic disease induced by ts1, a mutant of Moloney murine leukemia virus TB. Virology 180: 365-371.

Wong PKY, Prasad G, Hansen J, and Yuen PH (1989). ts1, a mutant of Moloney murine leukemia virus-TB, causes both immunodeficiency and neurologic disorders in BALB/c mice. Virology 170:450-459.

Wong PKY, Soong MM, and Yuen PH (1981). Replication of murine leukemia virus in heterologous cells: Interaction between ecotropic and xenotropic viruses. Virology 109:366-378.

Xia Z, Dickens M, Raingeaud J, Davis RJ, and Greenberg ME (1995). Opposing effects of ERK and JNK-p38 MAP kinases on apoptosis. Science 270:1326-1331.

Xiang J, Chao DT, and Korsmeyer SJ (1996). BAX-induced cell death may not require interleukin 1 beta-converting enzyme-like proteases. Proc Natl Acad Sci USA 93:1455914563.

Yang SI, Lickteig RL, Estes R, Rundell K, Walter G, and Mumby MC (1991). Control of protein phosphatase 2A by simian virus 40 small-t antigen. Mol Cell Biol 11:1988-1995.

Yang B and Prayson RA (2000). Expression of Bax, Bcl-2, and P53 in progressive multifocal leukoencephalopathy. Mod Pathol 13:1115-1120.

Yuen PH and Szurek PF (1989). The reduced virulence of the thymotrophic Moloney murine leukemia virus derivative MoMuLV-TB is mapped to 11 mutations within the U3 region of the long terminal repeat. J Virol 63:471-480.

Zachos G, Clements B, and Conner J (1999). Herpes simplex virus type 1 infection stimulates p38/c-Jun $\mathrm{N}$-terminal mitogen-activated protein kinase pathways and activates transcription factor AP-1. J Biol Chem 274:5097-5103. 